\title{
Research on the Application of Enterprise 6S Management Mode for Promoting College Students' Professional Quality
}

\author{
Yuan Wang \\ Shandong Agriculture and Engineering University, Shandong, Jinan, 250100
}

Keywords: 6S management mode; college students; professionalism

\begin{abstract}
The "6S" management model is a common on-site management model in modern enterprise management. Nearly $75 \%$ of enterprises around the world are widely implementing this model, and its development will inevitably have its own unique features. The introduction of this kind of management mode in colleges and universities can effectively create a workplace atmosphere and achieve a seamless connection between universities and enterprises to some extent. By standardizing and institutionalizing the management of the "6S" management model, students are guided to establish a sense of workplace, so that students can develop good habits and have excellent professional skills so that they can quickly integrate into the workplace.
\end{abstract}

\section{Introduction}

"6S" refers to the six aspects of Japanese sorting, rectification, cleaning, cleaning, literacy and safety. Because its Japanese Roman Pinyin starts with "S", it is simply referred to as "6S". Through the regulation of the scene and the present, it creates a good working environment and cultivates the comprehensive professional accomplishment of the staff. The ultimate goal is to improve the flat quality of the people, eliminate the sloppy psychology, and cultivate all things seriously. The ultimate goal of colleges and universities is to train high-quality, professional and comprehensive talents for the society, including not only the cultivation of students' basic knowledge and skills, but also the high professional ethics and comprehensive professional qualities of students. The reference of management means, the $6 \mathrm{~S}$ management mode is introduced into the management of colleges and universities, and the comprehensive professional quality of college students is improved.

\section{The Necessity of Introducing Enterprises into the 6S Management Mode of Enterprises}

\subsection{Adapt to the Needs of Enterprise Talents.}

Talent is an important force in social development, and the demand for talents has always been large. With the continuous development of the economy, people's indicators are constantly rising, and the requirements of enterprises for talents are constantly improving. Traditional technical talents are far from meeting the development needs of enterprises. In addition to the professional knowledge and skills, the requirements of the students are also very important to their comprehensive professional quality, mainly reflected in the five aspects of responsibility, honesty and trustworthiness, communication, team awareness and academic achievement. The ability of these aspects can not be formed overnight, but students are constantly cultivated in the process of learning. Applying the company's 6S management model to colleges and universities, students can develop good habits as soon as possible and improve their comprehensive quality to meet the needs of talents in the future.

\subsection{The Need to Train Technical Talents in Schools.}

The National Action Plan for Innovation and Development of Higher Vocational Education (2015-2018) pointed out that the cultivation of talents in colleges and universities should do a good job in the ideological and political education of students, not only to strengthen students' 
professional ethics, but also to strengthen their comprehensive quality. The students' skills and professional spirit are merged, their cultural literacy is continuously improved, and the mutual unity of knowledge learning, knowledge and skills and moral literacy is adhered to, and humanistic literacy and professional quality education are integrated into the program of talent training in colleges and universities. As an important base for cultivating talents, colleges and universities still have more deficiencies in the training of comprehensive quality talents. Constitute colleges and universities, strengthen school management, cooperate with enterprises, and actively introduce 6S management mode to create a management atmosphere for students and realize mutual unity between students and enterprises. Let the 6S management model affect students in a subtle way, internalize students' consciousness, and comprehensively improve students' professional quality.

\section{The Specific Practice of Introducing 6S Management Mode in Colleges and Universities}

In order to introduce the 6S management mode, colleges and universities must first carefully prepare and plan. Managers should take the lead, conduct long-term supervision and guidance, check and evaluate, and constantly improve and follow up according to the actual situation to ensure 6S. Management mode can produce certain effects and can be carried out sustainably.

\subsection{Implementation Principles.}

To fully implement the 6S management model, it is inevitable that everyone must participate in the transition from leadership to teachers to students. Colleges and universities are places for educating people. The introduction of the 6S management model is not only for students, but also for all teachers, but the number of students is larger. In this case, teachers and students need to work together to maximize the role of the 6S management model. Therefore, we must have a clear chain of responsibility and build a good management atmosphere.

Every job has a standard, and learning also has a standard of learning. Under this standard, there are clear learning objectives that continue to move toward high standards and improve efficiency. Once the standards are formed, they cannot be changed at will, so that the assessment system can proceed smoothly according to the standards. Students and teachers will continue to strengthen and enhance themselves according to the standards. In addition, the responsibilities should be clearly defined, and the functions of teachers should be carried out. Subdividing, the work assessment system is distributed to each department and students, so that the management of students can be standardized and institutionalized to the greatest extent, creating a clean, comfortable, stable and stable learning environment and living environment.

In fact, the introduction of the 6S management model is very simple, but it is difficult to run this model for a long time, and its effect can not be reflected in a short time, only the perseverance can see the effect. In order to effectively and permanently introduce the $6 \mathrm{~S}$ management model, we must adhere to the process from the outside to the inside, from simple to complex, from rough to fine, from image change to connotation improvement, complete a gradual process, and pay attention to the gradual improvement of details. Teachers and students work together to organize, clean, and safely, so that students can start from small things, start from the details, and change their thoughts through these small things and behaviors to form a good habit.

\subsection{Implementation Site and Content.}

Each office of the school formulates relevant rules and standards, and actively implements the health supervision of the inspectors and the inspection of public property in conjunction with the actual work requirements of their respective posts. The medical office and the security office of the university conduct 6S management on the epidemic prevention, transportation, and safety of the whole study.

Teaching 6S management requirements can be formulated and managed by the University Academic Affairs Office. The teachers and class guides in charge of the course are responsible for supervising the implementation of the $6 \mathrm{~S}$ standard for students, so as to remind the students to check after class, so that the students can complete the cleaning and rectification in time. 
The department and the departments are responsible for the guidance. Each class conducts the 6S management system of the class according to the actual situation, and organizes the students to carry out the active implementation and implementation. During the whole process, the counselor is responsible for the regular implementation of the students. Conduct an evaluation, announce the results of the inspection, reward the students who have implemented the good, correct the students who are not in place, and propose amendments and rectification measures.

The training base of colleges and universities is an important place for students to improve their professional ability. It is also the core place for their accumulated work experience and training ability. The training base of each university is mostly connected with the actual working environment of the enterprise. Therefore, for the training base the 6S management is very important, it can be said that the students can experience the enterprise workplace environment in advance. Attach importance to the construction of the 6S management culture of the training base and the formulation of relevant standard systems, including the clear job responsibilities, the clean and safe working environment, the protection and maintenance of equipment and facilities, and the regional division. Establish corresponding accounts, conduct real-time evaluation and announcement on the implementation of 6S management of the training base, and promptly propose suggestions and measures for improvement.

Dormitory is an important place for students' daily life, and most of the students' habits are also developed in the dormitory. The student office and the relevant management department are responsible for the guidance. Each dormitory shall formulate the detailed standards for the $6 \mathrm{~S}$ management of the dormitory according to the actual situation of the dormitory, and organize the students to carry out the implementation, and divide the work in the dormitory into a more reasonable and standardized division, and form a long-term Institutionalization, management personnel regularly check, evaluate, summarize and reflect on the 6S management of the dormitory, and hold meetings to discuss the health situation and work effects, and seek more efficient methods and systems. The dormitory department will construct a bulletin board for the $6 \mathrm{~S}$ management inspection and evaluation, announce the inspection results of each period, and propose suggestions and measures for improvement.

\section{Conclusion}

Promote the 6S management mode, and integrate with the school's various management activities and work, continuously deepen, create a good atmosphere from the shallow and deep, from the table and the inside, comprehensively enhance the comprehensive professional quality of the university, not only with The enterprise employs the standard to achieve perfect docking, and at the same time has a great impetus to the management of the school, and enhance the teaching image of the university. Through the reference to the $6 \mathrm{~S}$ management model of the enterprise, following the principle of full participation, adherence to efficiency, and gradual progress, the management model will be implemented in the office, teaching, class, training base and dormitory to realize the all-round improvement of students. The professional quality, create a safe, civilized, efficient and orderly environment, thus subtly affecting students, stimulating students' morale and responsibility, and cultivating their professionalism.

\section{References}

[1] Pan Weinan, Deng Shuixiu. Research on 6S Management Mode of Students in Higher Vocational Colleges [J]. Literature Education (2), 2018(05): 128-129.

[2] Liu Yamei, Yao Kai. Introducing the "6S" management mode of enterprises to improve the professional quality of vocational college students [J]. Education Modernization, 2017, 4(11): $199-200+210$.

[3] Chen Naihong. Analysis of 6S Management Mode of Practical Teaching Application_—Taking Nanjing City Vocational College as an Example [J].Wireless Interconnect Technology, 2016 (22): 
115-116.

[4] ZHANG Xiaowei, GONG Xuemei.Analysis of the Role of 6S Management Mode in Practical Teaching in Higher Vocational Colleges[J].Journal of Jilin Radio and Television University, 2013(05):21-22. 